\title{
Characteristics and Source Apportionment of Summertime Volatile Organic Compounds in a Fast Developing City in the Yangtze River Delta, China
}

\author{
Jie Zhang ${ }^{1,2, *(1)}$, Yu Zhao ${ }^{2,3}$, Qiuyue Zhao ${ }^{1}$, Guofeng Shen ${ }^{1}$, Qian Liu ${ }^{1}$, Chunyan Li ${ }^{1}$, \\ Derong Zhou ${ }^{1}$ and Shekou Wang ${ }^{1}$ \\ 1 Jiangsu Key Laboratory of Environmental Engineering, Jiangsu Academy of Environmental Sciences, \\ Nanjing 210036, China; zhaoqy@jshb.gov.cn (Q.Z.); azjlgd@gmail.com (G.S.); antmayiliu@163.com (Q.L.); \\ lcydejob@163.com (C.L.); zdr_jsaes@126.com (D.Z.); shekwang@163.com (S.W.) \\ 2 Jiangsu Collaborative Innovation Center of Atmospheric Environment and Equipment \\ Technology (CICAEET), Nanjing University of Information Science \& Technology, \\ Nanjing 210044, China; yuzhao@nju.edu.cn \\ 3 State Key Laboratory of Pollution Control \& Resource Reuse and School of the Environment, \\ Nanjing University, 163 Xianlin Ave., Nanjing 210023, China \\ * Correspondence: marie.jie@gmail.com; Tel.: +86-25-5852-7882
}

Received: 1 August 2018; Accepted: 22 September 2018; Published: 25 September 2018

\begin{abstract}
Volatile organic compounds (VOCs) are crucial for ozone formation in the Yangtze River Delta (YRD) in China. The characteristics of ambient VOCs in Nantong, a fast developing city in the YRD, were studied. Sixty ambient air samples were taken at five sites in three sampling days during summer time. One hundred and five VOCs were measured, showing that VOC concentration varied between $27.5 \mathrm{ppbv}$ to $33.1 \mathrm{ppbv}$ at five sites; these levels were generally lower than those for some big Chinese cities like Beijing, Shanghai and Nanjing. With larger fractions of alkanes, the Zilang (ZL) and Sanqu (SQ) sites had relatively higher VOC concentrations among the five sites. The oxidation formation potential (OFP) and secondary aerosol formation potential (SOAFP) were estimated to be $125 \mu \mathrm{g} / \mathrm{m}^{3}$ and $0.76 \mu \mathrm{g} / \mathrm{m}^{3}$, respectively. These two values were smaller than those in other big cities, as they were dominated by aromatic compounds (e.g., toluene and benzene) of which concentrations in Nantong were found to be lower. The highest toluene concentration was measured in ZL, implying substantial effects of surface coating industry near the site. Through the Positive Matrix Factorization (PMF) model, the identified sources of VOCs included LPG (Liquefied petroleum gas) combustion $(13.9 \%)$, chemical industry $(8.5 \%)$, natural gas use $(15.6 \%)$, gasoline evaporation $(12.8 \%)$, petrol industry use $(11.8 \%)$, solvent use $(16.2 \%)$ vehicle exhausts $(12.1 \%)$ and surface coating $(9.2 \%)$. A relatively small contribution from vehicles was found in Nantong compared with other big cities. Moreover, LPG emissions were identified to be relatively important in Nantong, indicated by the large mass fraction of propane and ethane concentrations in the atmosphere.
\end{abstract}

Keywords: VOCs; OFP; SOAFP; source apportionment; China

\section{Introduction}

Volatile organic compounds (VOCs) are a group of pollutants contributing to the formation of ozone and secondary organic aerosols (SOAs) which affect human health, damage plants, and decrease visibility [1]. Derwent (2017) [2] reported a 30\% VOC abatement could achieve a 10-15\% ozone reduction in North America, according to Master Chemical Mechanism (MCM) model estimation. Based on observation at two sites in the UK between 1999 and 2012, ethane and m+p-xylene were found to be the most effective species among 27 anthropogenic VOCs in reducing ozone [3]. However, 
the ozone reduction rate was affected by whether the ozone formation was VOC limited or NOx limited, and it was influenced by background VOCs and NOx levels and meteorological conditions [1,4]. Therefore, the impact of VOCs on ozone formation is complicated, requiring more detailed information (e.g., ambient pollutant concentration) to estimate the effect. Besides ozone, VOCs could also affect SOA formation from a short period after emission $[5,6]$. VOCs were reported to contribute to $15-23 \%$ of SOA formation by in situ sampling and modelling [7,8]. In addition, the SOA formation potential was found to increase by around three times due to the growth of VOC concentration in heavy hazy days [9].

The Yangtze River Delta (YRD) is one of the most developed regions in China, with continuous large growth rate of GDP. The ozone pollution in the YRD has been recorded to be exceeding the air quality standard by more than $100 \%$ with an even worsening trend [10]. The ozone pollution in the YRD was expected to be VOCs limited by studies using the Observation Based Model (OBM), air quality modelling and satellite observation [10-13]. The VOC emission characteristics in Jiangsu province in the YRD were unique. It was found to be dominated by solvent use, industry processes and transportation, which contributed 39\%, 38\% and $11 \%$ to the total provincial emissions, respectively [14]. The large contribution of industry was also indicated by a source apportionment study, which suggested that industrial production accounts for $45-63 \%$ of VOCs in the ambient air in Nanjing in the YRD [15].

The contribution of industrial emission in the YRD was generally higher than that of Beijing and the Pearl River Delta (PRD), while that of transportation was relatively lower. Huang et al. (2011) [16] reported the contribution of industrial processes, domestic solvent use and vehicular emissions to the total amount of VOCs in the YRD was $68 \%, 20 \%$ and $12 \%$, respectively. Emission inventory studies in Beijing showed vehicular and industrial sources contributed $35-51 \%$ and $10-41 \%$, respectively [17-19]. A contribution of $49 \%$ from vehicles in Beijing was also reported by a VOC source apportionment study [20]. Emission inventory in the PRD showed that industrial solvent use, industrial processes and vehicular emissions contributed $39 \%, 18 \%$ and $28 \%$ to total VOC emissions, respectively [21]. Louie et al. (2013) [22] also found that vehicular and industrial use are the two main VOC sources in the PRD based on ambient air monitoring.

Nantong is a coastal city in the YRD just to the north of Shanghai, suffering severe ozone pollution, and the standard of daily maximum $8 \mathrm{~h}$ average ozone concentration was exceeded in $40 \%$ of the days in August 2013. It is a city with a GDP growth rate of 11.5\% during 2010-2014, larger than the average level in the YRD. The increment was mainly from industry development, including chemical and shipbuilding industries. Due to intensive use of VOC materials and solvents in these industries, VOC emissions are increasing in Nantong. Zheng et al. (2016) [23] pointed out that both VOC growth amount $(3.5 \mathrm{Gg})$ and growth rate $(20.1 \%)$ in Nantong were in the largest city group in the Jiangsu province from 2009 to 2013. However, the ambient VOC characteristics of relatively small but fast developing cities have not been well studied in China. Published studies on VOCs were mainly carried out in Beijing, Shanghai, Guangzhou and some other big cities, e.g., Nanjing in the YRD [24-27]. Therefore, it is also important to understand the pollution pattern and to quantify the source contributions during the fast developing period.

Nevertheless, large scale chemical industrial parks in the YRD were located along the Yangtze River, which flows from west to east. During summer, wind direction was mainly easterly; therefore, the VOC emissions could be transported to the western YRD and other inland cities. However, previous studies in the YRD were mainly carried out in Shanghai and Nanjing, and other parts of the YRD were seldom evaluated. The study carried out in Nantong can help understand the effect of regional VOC transportation on ozone formation in the YRD.

Currently, most VOC studies in the YRD are conducted at a single sampling site. By characterizing the ambient VOCs at several sites in different areas, this study intends to provide a more comprehensive understanding of VOC pollution in the city. It is thus necessary to characterize the pollution condition of VOCs and to estimate the formation potential of ozone. Moreover, quantitative source contribution 
of VOCs remained unclear in the city due to lack of source apportionment analysis. In general, therefore, current work conducted in a fast developing city could help to get a full picture of VOCs and ozone pollution in China.

\section{Methods}

\subsection{VOC Sampling}

The VOC samples were taken at five different sites in Nantong: Hongqiao ( $\mathrm{HQ}, 32.05^{\circ} \mathrm{N}$, $\left.120.81^{\circ} \mathrm{E}\right)$, Xinghu $\left(\mathrm{XH}, 32.01^{\circ} \mathrm{N}, 120.86^{\circ} \mathrm{E}\right)$, Zilang $\left(\mathrm{ZL}, 31.93^{\circ} \mathrm{N}, 120.95^{\circ} \mathrm{E}\right)$, Sanqu in the economic developing sector (SQ, $\left.31.85^{\circ} \mathrm{N}, 120.96^{\circ} \mathrm{E}\right)$ and Sutong bridge $\left(\mathrm{ST}, 31.82^{\circ} \mathrm{N}, 121.00^{\circ} \mathrm{E}\right)$. HQ was in the central urban commercial and residential area. $\mathrm{XH}$ was located in a residential area near the chemical industry park. ZL was located in an area surrounded by boat and container painting businesses. SQ was set in an industry park of rubber, plastic, resin and other chemical production. ST was located in an open square near the Yangtze River, about $200 \mathrm{~m}$ away from a heavy traffic bridge. The location of the sampling sites in Nantong is shown in Figure 1. The background blue color indicated industrial areas and yellow color indicated commercial and residential areas. The five sampling sites were selected to reflect VOC concentration in residential, commercial and industrial areas with relative high population density.

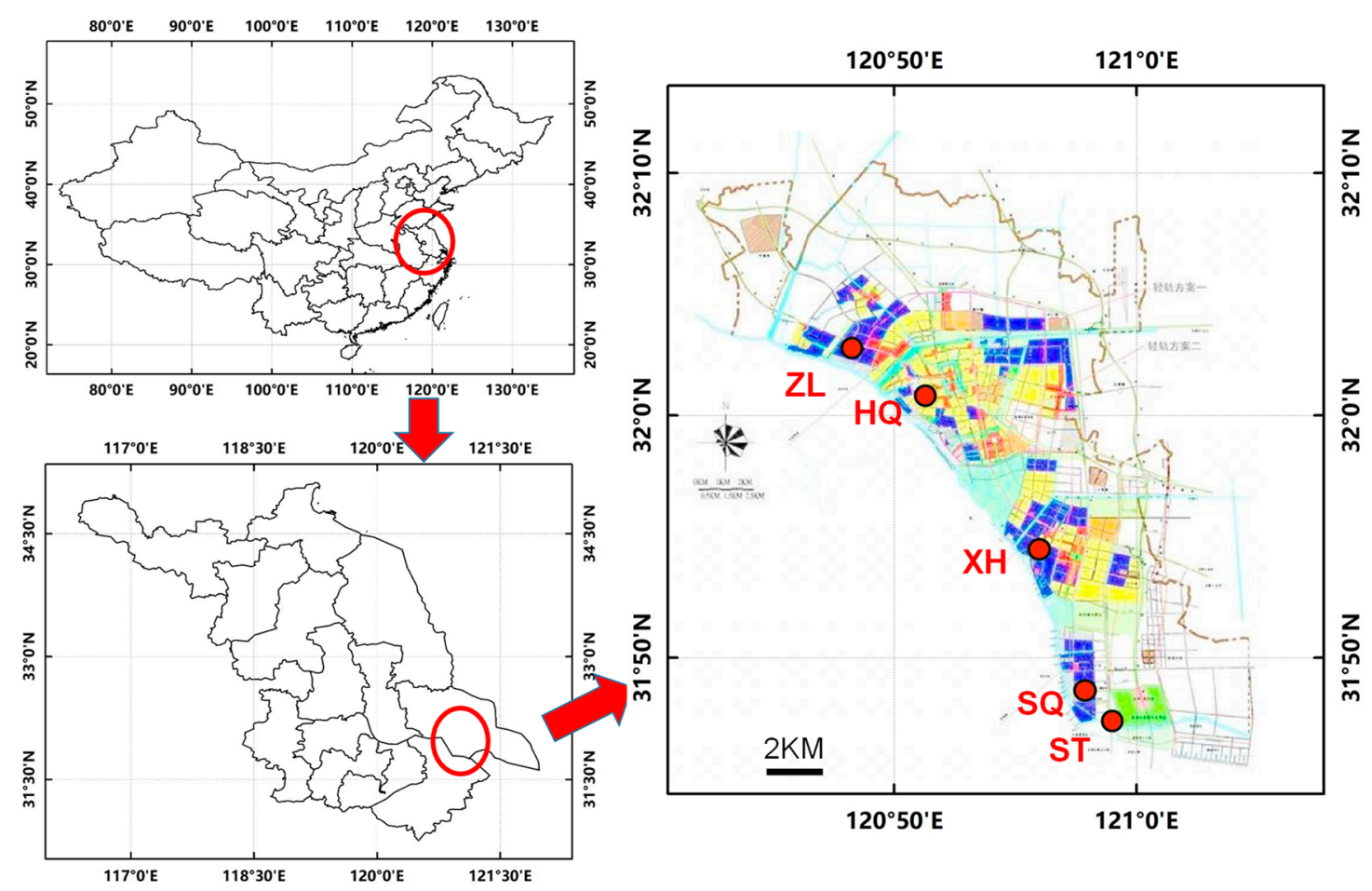

Figure 1. Sampling sites location in Nantong. The background blue color indicates industrial areas and yellow color indicates commercial and residential areas. $\mathrm{ZL}=$ Zilang. $\mathrm{HQ}=$ Hongqiao. $\mathrm{XH}=\mathrm{Xinghu}$. $\mathrm{SQ}=$ Sanqu. ST $=$ Sutong.

The sampling lasted for three days from 30 July 2014 to 1 August 2014. Hourly samples were taken by stainless steel canisters ( 6 L, Entech Instruments, Inc., Simi Valley, CA, USA) four times a day, i.e., 7:30-8:30, 10:30-11:30, 13:30-14:30 and 16:30-17:30, representing the VOC concentrations at 8:00, 11:00, 14:00 and 17:00, respectively. In total, 60 samples were collected during the current study.

\subsection{Analytic Methods}

Up to 105 target organic compounds were measured with the U.S. Environmental Protection Agency (EPA) Compendium Method TO-15 [28]. The samples were pumped into the pre-concentrator 
before analysis in three steps. In the first step, the sample was trapped with liquid nitrogen at the temperature of $-150{ }^{\circ} \mathrm{C}$ and recovered by desorbing at $10^{\circ} \mathrm{C}$ to remove $\mathrm{H}_{2} \mathrm{O}, \mathrm{N}_{2}, \mathrm{CO}_{2}, \mathrm{CO}$, and $\mathrm{O}_{2}$. In the second step, the sample was cooled to $-30{ }^{\circ} \mathrm{C}$ and released at $180{ }^{\circ} \mathrm{C}$ to remove $\mathrm{CO}_{2}$. Thirdly, the VOC sample was frozen at $-160^{\circ} \mathrm{C}$ to concentrate the sample. A DB-624 column $(60 \mathrm{~m} \times 0.25 \mathrm{~mm})$ was used in the GC (Gas Chromatography) with the following temperature program: $-50{ }^{\circ} \mathrm{C}(7 \mathrm{~min}) ;-50{ }^{\circ} \mathrm{C}$ to $180{ }^{\circ} \mathrm{C}$ at the rate of $4{ }^{\circ} \mathrm{C} / \mathrm{min} ; 180{ }^{\circ} \mathrm{C}$ to $220^{\circ} \mathrm{C}$ at the rate of $15{ }^{\circ} \mathrm{C} / \mathrm{min}$; $220^{\circ} \mathrm{C}$ ( $3 \mathrm{~min}$ ). The VOC concentrations were quantified using the internal standard method, in which bromochloromethane, 1,2-difluorobenzene and chorobenzene- $\mathrm{d} 5$ were used as the internal standard compounds. The method detection limit was $0.1 \mathrm{ppbv}$ for each compound. The ethene information was not available in the current study, because we only used MS (Mass Spectrometry) but without a FID (flame ionization detector) to detect the compounds; therefore, the peak of ethene was not differentiated well during the test. The chromatograph of standard sample and collected ambient air sample measured by TO-15 is illustrated as Figures S1 and S2 in Supplementary Material. The canisters were pre-cleaned using ultra-pure nitrogen $\left(\mathrm{N}_{2}, 99.999 \%\right)$ to eliminate organic compounds before sampling. Blank samples were taken to evaluate the analysis performance and no compound was detected. However, a storage blank was not taken in this study.

A calibration curve of target compounds was performed at five different intake volumes (10 ppb at $50 \mathrm{~mL}, 100 \mathrm{~mL}, 300 \mathrm{~mL}, 500 \mathrm{~mL}$ and $800 \mathrm{~mL}$ ). The correlation coefficients were above 0.99 . The cryogenic pre-concentrator was baked after each analysis. In order to ensure the stability, the response of the instrument to VOCs was calibrated after every $24 \mathrm{~h}$ using standard runs of a calibration gas with ambient concentrations.

\subsection{Positive Matrix Factorization (PMF) Receptor Model}

The Positive Matrix Factorization (PMF) model 5.0 developed by the U.S. EPA was applied to generate source contribution without source profile. The source contribution for each sample was calculated as follows [29]:

$$
x_{i j}=\sum_{k=1}^{p} g_{i k} f_{k j}+e_{i j}
$$

where $x_{i j}$ represents the contribution of $j$ th species in $i$ th sample; $p$ represents the number of sources, $g_{i k}$ represents source contribution of $k$ th source to $i$ th samples; $f_{k j}$ represents the fraction of $j$ th species in $k$ th source in species profile; $e_{i j}$ represents the residual of $j$ th species in $i$ th sample. In our current study, 25 species were selected and a total number of 60 samples were input in the PMF model.

\section{Results and Discussion}

\subsection{Characteristics of VOC Species}

The VOC concentrations at different sampling sites were illustrated in Figure 2, with the 15 most abundant species highlighted individually and all the other compounds grouped together. The concentration of total detected VOCs was within the range of 27.5-33.1 ppbv. The five compounds with the highest concentration were propane, ethane, isopropyl alcohol, acetylene and N-pentane, and the averaged concentrations for them were $2.8 \mathrm{ppbv}, 2.7 \mathrm{ppbv}, 2.3 \mathrm{ppbv}, 2.2 \mathrm{ppbv}$ and $1.6 \mathrm{ppbv}$, consisting of $9 \%, 9 \%, 8 \%, 7 \%$ and $6 \%$ of total VOCs, respectively. The collected mass fraction of the five species consisted of $40 \%$ of total VOCs concentration. Among the five sites, the largest and smallest concentrations of total VOCs was found at ZL and ST, respectively. The difference mainly came from ethane, which had variance of $3 \mathrm{ppb}$ between the highest and lowest sites. It could be largely emitted through leaking during LNG (Liquefied Natural Gas) storage and transportation, due to the large amount of LNG consumed in the chemical industry parks of ZL and SQ. 

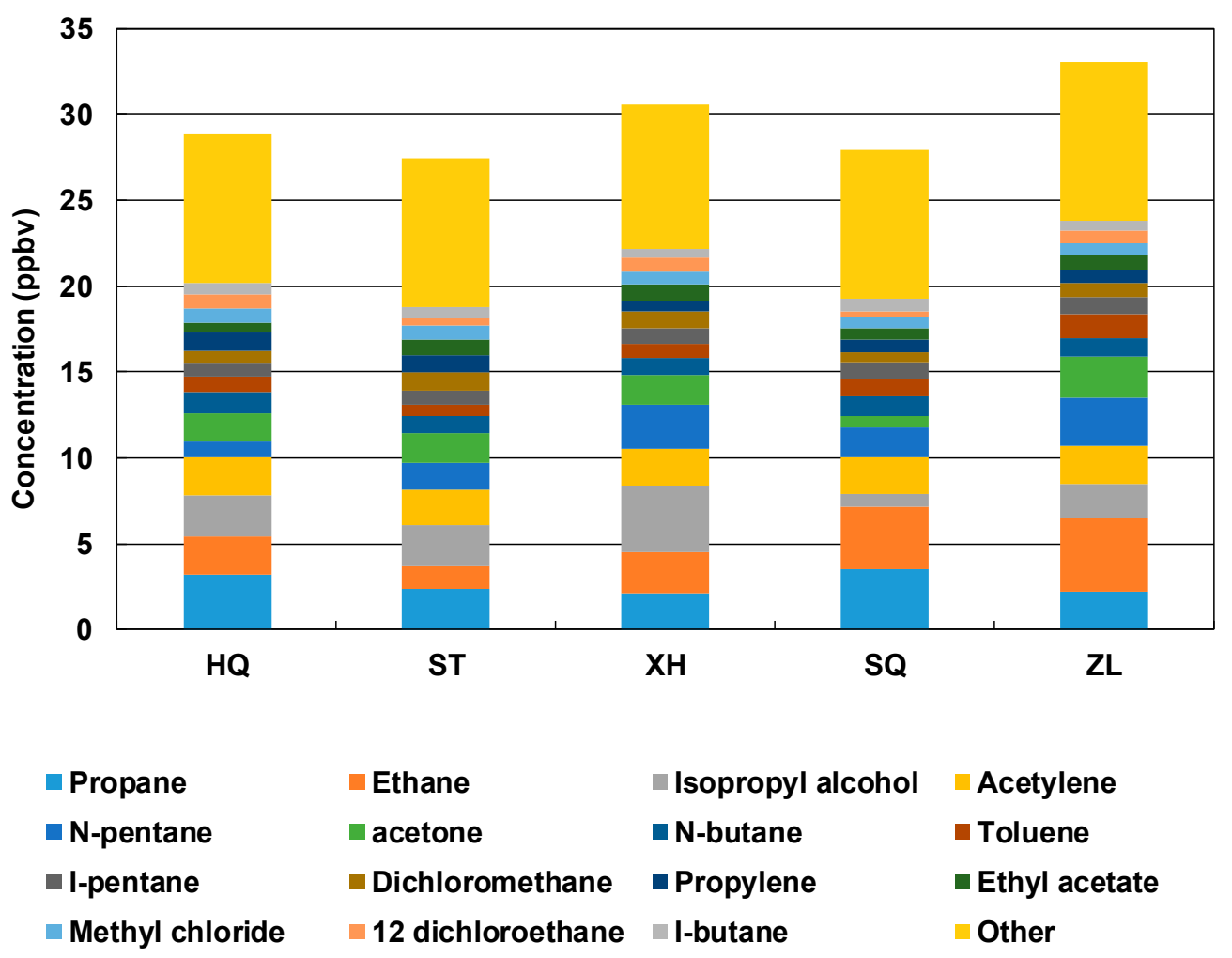

Figure 2. Volatile organic compound (VOC) concentrations at the five sampling sites.

The ratio of benzene/toluene $(\mathrm{B} / \mathrm{T})$ was used to estimate the influence of vehicle or industry emissions [30,31]. Barletta et al. (2005) [30] reported a B/T of $<0.6$ to be vehicle emission dominated and $\mathrm{a} / \mathrm{T}$ of $>1$ to be coal and biofuel burning dominated. The value of the $\mathrm{B} / \mathrm{T}$ for Nantong, Beijing, Shanghai, Nanjing and Guangzhou was $0.45,0.62,0.35,1.09$ and 0.34 , respectively. For Beijing and Guangzhou, the B/T method was in accordance with the source apportionment study, which showed the contribution of vehicle emissions to ambient VOC level in Beijing and Guangzhou to be $43 \%$ and $52.5 \%$, respectively $[32,33]$. In contrast, although the B/T in Shanghai was low, the contribution of vehicles to atmospheric VOC concentration was only 21\% [33]. Moreover, the B/T in Nanjing was larger than one, even though the contribution of coal and biofuel burning to ambient VOC concentration was estimated only at $28 \%$ [31]. Since source apportionment studies showed solvent use and industrial emissions contributed a large percentage to atmospheric VOC concentration in the YRD (e.g., $42 \%$ for Shanghai and 31\% for Nanjing) [31,33], the main VOC source in Nantong could not be simply defined as vehicular emission, although the B/T value in Nantong was as low as 0.45 .

The low B/T value in Nantong may also be influenced by the surrounding environment near the sampling sites. The ratio of benzene to toluene in emissions was 0.42 and 0.45 for Nantong and Nanjing, respectively [14], suggesting a similar emission pattern in the two cities. The sampling sites in Nantong were in urban areas and industrial parks, while the monitoring site in Nanjing was located $20 \mathrm{~km}$ away from the urban center, with industrial parks several kilometers away [26], indicating the effect of local emissions and diffusion conditions could induce different $\mathrm{B} / \mathrm{T}$ values in the two cities.

\subsection{Ozone and SOA Formation Potential}

VOCs contributed to ozone formation through oxidation and subsequent reactions. It has been reported that Shanghai was VOCs limited in ozone photochemical production [27]. Nantong is in the vicinity area of Shanghai and may share the same characteristics. The oxidation formation potential (OFP) in the current study was estimated as follows [34].

$$
O F P_{i}=V O C_{i} \times M I R_{i}
$$


where $V O C_{i}$ is the concentration of $i$ th $V O C ; M I R_{i}$ is the maximum incremental reactivity of $i$ th compound, and the values were taken from Carter (1994) [35].

Since VOCs could also contribute to the formation of secondary organic aerosols (SOAs) and deteriorate particle pollution, the potential of SOA formation from VOCs was estimated in the current study. The secondary organic aerosol formation potential (SOAFP) was estimated as follows.

$$
\begin{gathered}
\operatorname{SOAFP}_{i}=\operatorname{VOC}_{i 0} \times F A C_{i} \\
V C_{i}=V O C_{i 0} \times\left(1-F_{V O C i r}\right)
\end{gathered}
$$

where $V O C_{i 0}$ is the initial concentration of $i$ th VOC; $F A C_{i}$ is the fractional aerosol coefficient of $i$ th VOC [36]; and $F_{V O C i r}$ is the fraction of $i$ th VOCs involved in the reaction [36]. In the current study, 11 species were included in the SOAFP estimation, including four alkanes and seven aromatics.

The results of the OFP and SOAFP are listed in Table 1. The aromatics had the highest OFP and SOAFP, although the concentration of aromatics was $11.0-17.5 \mu \mathrm{g} / \mathrm{m}^{3}$, consisting of $19-24 \%$ of the total mass of VOCs. The order of concentration was alkanes $(50 \%)>$ aromatics $(22 \%)>$ alcohols $(10 \%)$ $>$ ketones $(9 \%)>$ alkenes $(6 \%)>$ acetylene $(4 \%)$, while that of the OFP was aromatics $(43 \%)>$ alkenes $(27 \%)>$ alkanes $(23 \%)>$ ketones $(3 \%)=$ alcohols $(3 \%)>$ acetylene $(1 \%)$. For the SOAFP, only alkanes and aromatics had the corresponding formation potential [36]. The result was also in accordance with other studies in Beijing and Shanghai [37,38]. Among the five sites, ZL had the largest OFP and SOAFP, due to its highest concentration of aromatics $\left(17.5 \mu \mathrm{g} / \mathrm{m}^{3}\right.$ comparing to $11.0-14.5 \mu \mathrm{g} / \mathrm{m}^{3}$ in the other four sites). The two main aromatics species in ZL were toluene and benzene, and their concentrations were $70 \%$ and $20 \%$ larger than the average of other four sites, respectively.

Table 1. The oxidation formation potential (OFP) and secondary organic aerosol formation potential (SOAFP) for different VOC categories at each site.

\begin{tabular}{ccccccccccc}
\hline \multirow{2}{*}{ Site } & \multicolumn{9}{c}{ OFP $\left(\mu \mathrm{g} / \mathrm{m}^{\mathbf{3}}\right)$} & \multicolumn{3}{c}{ SOAFP $\left(\mu \mathrm{g} / \mathrm{m}^{3}\right)$} \\
\cline { 2 - 10 } & Alkanes & Alkenes & Acetylene & Aromatics & Ketones & Alcohols & Total & Alkanes & Aromatics & Total \\
\hline HQ & 25.27 & 37.53 & 1.30 & 51.46 & 3.97 & 3.43 & 122.96 & 0.01 & 0.74 \\
ST & 26.84 & 39.10 & 1.19 & 46.01 & 3.59 & 3.44 & 120.17 & 0.01 & 0.61 & 0.62 \\
XH & 29.41 & 26.72 & 1.22 & 42.44 & 3.75 & 5.65 & 109.18 & 0.01 & 0.64 & 0.65 \\
SQ & 31.23 & 37.18 & 1.26 & 55.57 & 1.77 & 1.05 & 128.07 & 0.01 & 0.76 & 0.77 \\
ZL & 32.38 & 29.29 & 1.30 & 75.16 & 5.54 & 2.84 & 146.51 & 0.01 & 0.99 & 1.00 \\
\hline
\end{tabular}

The averaged OFP value was $125 \mu \mathrm{g} / \mathrm{m}^{3}$, around $48 \%$ less than that obtained in Beijing by Zhang et al. (2017) [37]. Our OFP value was also lower than those in given northern or southern China cities [34] due to the relatively low VOC concentration in Nantong. Consistent with this work, aromatics dominated the OFP in 20 out of 22 cities in Zhang et al. (2017) [34]. In other studies in Beijing and Nanjing, however, alkenes were the largest contributor to the OFP [31,37]. Since concentrations of different VOC species varied by year and season [37], more studies on temporal variation are needed to identify the contribution to the OFP. The SOAFP in the current study was $49 \%$ smaller than the results in Beijing, since the concentration of aromatics was $41 \%$ less [37]. Compared to most other Chinese cities, the SOAFP in the current study was much smaller due to relatively low aromatic concentrations [34].

There are several limitations in the current study. Ethene was not included since it was not well detected, leading to an underestimation in OFP. Moreover, carbonyls, isoprene, pinene and some oxygenated VOCs which had relatively high fractional aerosol coefficients (FACs) was not included in the current study due to the limited sampling and measurement method. In order to estimate the contribution of VOCs to ozone and SOA formation more thoroughly, more species should be measured in future studies. In addition, the FAC was an empirical factor from a smoke chamber study [38], and it may vary with actual circumstances of different solar radiation, humidity, particulate concentration, 
chemical compounds, etc. Further studies on VOCs and their corresponding particle phase oxidation products would help to understand the process better.

\subsection{Source Apportionment of VOCs}

In the current study, the source contribution of VOCs was identified with the PMF model. Twenty-five species were selected for the model, since they had relatively abundant concentrations and were typical species from different emission sources. Missing data was substituted by the geometric mean concentration with four times the uncertainty [39,40]. Bootstrap analyses were run 100 times for each scenario with different numbers of factors/sources. $Q$ is goodness-of-fit parameter for the PMF model, while $Q_{\text {expected }}$ is the $Q$ value for number of strong correlated species. $Q / Q_{\text {expected }}$ represents the sum of squared scaled residuals over all species, divided by the number of species. When the number of factors continues to increase, the change of $\mathrm{Q} / \mathrm{Q}_{\text {expected }}$ is not as strong, indicating that maybe too many factors were being fit. In the current study, we selected eight factors according to the $\mathrm{Q} / \mathrm{Q}_{\text {expected }}$ variation. The concentration and contribution of each factor are summarized by species in Table 2.

Factor 1 was suggested to be LPG combustion, contributed to by a larger percentage of propane and propylene, consisting of $41 \%$ and $45 \%$ of the total concentration, respectively. These two species were suggested to be largely emitted from LPG combustion [41,42]. Factor 2 was suggested to be the chemical industry. It contained a relatively large contribution of dichloromethane and ethyl acetate, which was widely applied in esters and acetate fiber production in Nantong. Factor 3 contained a high contribution of ethane (61\%), representing the source of natural gas use. The ethane could be emitted from natural gas leaking in the transport system and refueling process. Factor 4 could be gasoline evaporation. This factor contained a relatively high contribution of n-pentane, i-pentane, benzene and toluene, which reflected the important roles of gasoline evaporation [41,43]. Factor 5 was identified as the petrol industry. It contained a relatively large fraction of alkanes and a series of alkenes and aromatic species which could be emitted from refineries. Factor 6 could be solvent use. This factor included a high contribution (93\%) of acetone, which was used as surface cleaning substance. Factor 7 represented vehicle exhaust, with relatively more i-pentane, n-butene and acetylene. Those species were typical tracers for vehicle emissions [15,41]. Factor 8 was suggested to be surface coating sources, showing a high percentage of toluene, $p$-xylene, ethylbenzene, $p$-xylene, m-xylene, $\mathrm{o}-x y l e n e$ and benzene. Those compounds are used widely in paint for surface coating [44]. In general, the contributions to VOC concentration were $13.9 \%, 8.5 \%, 15.6 \%, 12.8 \%, 11.8 \%, 16.2 \%, 12.1 \%$ and $9.2 \%$ for LPG combustion, the chemical industry, natural gas use, gasoline evaporation, the petrol industry, solvent use, vehicle exhaust and surface coating, respectively. 
Table 2. Positive Matrix Factorization (PMF) source apportionment result. Conc. represents concentration of each compound. Percentage represents the contribution of each compound in the total amount of each factor.

\begin{tabular}{|c|c|c|c|c|c|c|c|c|c|c|c|c|c|c|c|c|}
\hline & \multicolumn{2}{|c|}{ Factor 1} & \multicolumn{2}{|c|}{ Factor 2} & \multicolumn{2}{|c|}{ Factor 3} & \multicolumn{2}{|c|}{ Factor 4} & \multicolumn{2}{|c|}{ Factor 5} & \multicolumn{2}{|c|}{ Factor 6} & \multicolumn{2}{|c|}{ Factor 7} & \multicolumn{2}{|c|}{ Factor 8} \\
\hline & Conc. & $\%$ & Conc. & $\%$ & Conc. & $\%$ & Conc. & $\%$ & Conc. & $\%$ & Conc. & $\%$ & Conc. & $\%$ & Conc. & $\%$ \\
\hline Ethane & 0.00 & 0 & 0.00 & 0 & 1.76 & 61 & 0.34 & 12 & 0.76 & 27 & 0.00 & 0 & 0.00 & 0 & 0.00 & 0 \\
\hline Propane & 1.12 & 41 & 0.00 & 0 & 0.31 & 11 & 0.00 & 0 & 0.37 & 14 & 0.04 & 2 & 0.53 & 19 & 0.37 & 14 \\
\hline N-butane & 0.12 & 12 & 0.02 & 2 & 0.03 & 3 & 0.18 & 18 & 0.15 & 14 & 0.07 & 7 & 0.34 & 33 & 0.13 & 12 \\
\hline Isobutane & 0.10 & 19 & 0.00 & 0 & 0.01 & 1 & 0.00 & 0 & 0.13 & 24 & 0.08 & 14 & 0.18 & 34 & 0.04 & 8 \\
\hline N-pentane & 0.05 & 3 & 0.00 & 0 & 0.09 & 5 & 0.96 & 54 & 0.00 & 0 & 0.67 & 38 & 0.00 & 0 & 0.00 & 0 \\
\hline Isopentane & 0.00 & 0 & 0.07 & 7 & 0.10 & 11 & 0.19 & 22 & 0.00 & 0 & 0.00 & 0 & 0.40 & 46 & 0.12 & 14 \\
\hline N-hexane & 0.02 & 7 & 0.03 & 8 & 0.00 & 1 & 0.02 & 5 & 0.14 & 45 & 0.01 & 4 & 0.05 & 17 & 0.04 & 13 \\
\hline 2-methylhexane & 0.03 & 17 & 0.02 & 13 & 0.02 & 12 & 0.00 & 0 & 0.03 & 17 & 0.03 & 15 & 0.03 & 16 & 0.02 & 10 \\
\hline Cyclopentane & 0.02 & 11 & 0.00 & 0 & 0.01 & 6 & 0.04 & 25 & 0.02 & 14 & 0.04 & 21 & 0.03 & 19 & 0.01 & 4 \\
\hline 2,3-dimethylpentane & 0.04 & 26 & 0.01 & 4 & 0.02 & 11 & 0.02 & 15 & 0.01 & 7 & 0.04 & 25 & 0.02 & 11 & 0.00 & 1 \\
\hline 3-methylheptane & 0.02 & 14 & 0.02 & 14 & 0.01 & 9 & 0.03 & 19 & 0.00 & 2 & 0.04 & 25 & 0.02 & 11 & 0.01 & 5 \\
\hline N-octane & 0.09 & 33 & 0.05 & 18 & 0.03 & 12 & 0.08 & 29 & 0.02 & 6 & 0.00 & 0 & 0.01 & 2 & 0.00 & 0 \\
\hline Propylene & 0.35 & 45 & 0.15 & 19 & 0.02 & 3 & 0.16 & 21 & 0.08 & 10 & 0.01 & 1 & 0.00 & 0 & 0.01 & 2 \\
\hline N-butene & 0.03 & 17 & 0.01 & 6 & 0.00 & 0 & 0.01 & 4 & 0.04 & 21 & 0.04 & 20 & 0.05 & 30 & 0.00 & 3 \\
\hline 1-pentene & 0.04 & 21 & 0.03 & 16 & 0.05 & 25 & 0.04 & 23 & 0.00 & 0 & 0.00 & 0 & 0.03 & 14 & 0.00 & 0 \\
\hline Acetylene & 0.46 & 22 & 0.19 & 9 & 0.28 & 13 & 0.00 & 0 & 0.39 & 18 & 0.32 & 15 & 0.44 & 21 & 0.05 & 2 \\
\hline benzene & 0.02 & 5 & 0.00 & 0 & 0.03 & 9 & 0.14 & 42 & 0.03 & 9 & 0.00 & 0 & 0.04 & 13 & 0.07 & 21 \\
\hline Toluene & 0.00 & 0 & 0.06 & 7 & 0.00 & 0 & 0.21 & 26 & 0.06 & 7 & 0.00 & 0 & 0.04 & 4 & 0.46 & 56 \\
\hline P-xylene & 0.01 & 2 & 0.07 & 24 & 0.00 & 0 & 0.05 & 18 & 0.00 & 0 & 0.02 & 6 & 0.03 & 9 & 0.12 & 41 \\
\hline Ethylbenzene & 0.02 & 9 & 0.00 & 0 & 0.04 & 19 & 0.00 & 0 & 0.00 & 0 & 0.02 & 10 & 0.03 & 14 & 0.11 & 48 \\
\hline M-xylene & 0.03 & 23 & 0.01 & 6 & 0.03 & 22 & 0.00 & 0 & 0.03 & 18 & 0.01 & 9 & 0.00 & 0 & 0.03 & 22 \\
\hline O-xylene & 0.02 & 13 & 0.01 & 6 & 0.03 & 21 & 0.00 & 1 & 0.01 & 7 & 0.02 & 13 & 0.01 & 9 & 0.05 & 29 \\
\hline acetone & 0.00 & 0 & 0.12 & 7 & 0.00 & 0 & 0.00 & 0 & 0.00 & 0 & 1.60 & 93 & 0.00 & 0 & 0.00 & 0 \\
\hline Dichloromethane & 0.08 & 11 & 0.39 & 53 & 0.11 & 15 & 0.00 & 0 & 0.00 & 0 & 0.09 & 12 & 0.07 & 9 & 0.00 & 0 \\
\hline Ethyl acetate & 0.00 & 0 & 0.41 & 69 & 0.04 & 7 & 0.00 & 0 & 0.01 & 2 & 0.00 & 0 & 0.00 & 0 & 0.13 & 22 \\
\hline
\end{tabular}


The PMF results showed a small contribution of vehicle exhaust an a large contribution of natural gas in Nantong. The contribution of vehicle exhaust in Nantong (12.1\%) was much lower than that of Beijing (43.2\%), Guangzhou (51.1\%), and Nanjing (26.0\%) [26,32], resulting partly from a lower vehicle population in Nantong. Given the times of those source apportionment studies, the vehicle populations were 1.0 million, 2.6 million, 1.75 million and 1.7 million in Nantong (2014), Beijing (2005), Guangzhou (2004) and Nanjing (2013), respectively. Moreover, the difference could also come from varied emission control stages for vehicles between cities. In the studies of Beijing and Guangzhou, vehicle emission standards were National II (equal to Euro II), while the more stringent standard National IV (equal to Euro IV) was applied in Nantong when this work was conducted. The contribution of natural gas in Nantong was 15.6\%, 2.3 times higher than that of 4.7\% in Beijing. This large contribution in Nantong was attributed to the leakage from large storage and transportation facilities of natural gas in industry parks.

There are still limitations in the current source apportionment work. Some of the sources were not identified clearly (e.g., the petrol and chemical industries), since they shared a large number of compounds and were differentiated by percentage of certain compounds in each source. It is suggested to separate the petrol and chemical industries into several categories with specific compounds for each category. Certain species (e.g., MTBE, Methyl Tert-Butyl Ether) should also be included to differentiate gasoline evaporation and gasoline exhaust.

\section{Conclusions}

Ambient VOCs at different sites representing industrial, commercial and residential areas in Nantong were measured in summer 2014. The concentrations ranged from 27.5-33.1 ppbv at the five sites, and those in ZL and SQ were larger due to more ethane that may come from leakage of LNG storage and transportation. Eleven major species of alkanes, alkenes, acetylene and aromatics were selected to compare with the other studies in China. The concentrations of those species in Nantong were generally smaller than those in other big cities in China, although Nantong had a comparable VOC emission intensity to Beijing and Nanjing. Better diffusion conditions were thus expected in Nantong. The OFP and SOAFP of VOCs were estimated, ranging from $109 \mu \mathrm{g} / \mathrm{m}^{3}$ to $147 \mu \mathrm{g} / \mathrm{m}^{3}$ and $0.62 \mu \mathrm{g} / \mathrm{m}^{3}$ to $1.00 \mu \mathrm{g} / \mathrm{m}^{3}$, respectively. The largest OFP and SOAFP were found at ZL, due to its high aromatics concentration from the surface coating industry. It was also implied that toluene and benzene were the two dominant species for both ozone and SOA formation in Nantong. In the future, more attention needs to be paid to carbonyls and other oxygenated VOCs which also play an important role in ozone and SOA formation. The contribution of LPG combustion, the chemical industry, natural gas use, gasoline evaporation, the petrol industry, solvent use, vehicle exhaust and surface coating were estimated at $13.9 \%, 8.5 \%, 15.6 \%, 12.8 \%, 11.8 \%, 16.2 \%, 12.1 \%$ and $9.2 \%$, respectively with the PMF model. A lower contribution of vehicles and larger contribution of natural gas leakage was found in Nantong compared with big cities. More species are suggested to be measured in the future to better differentiate source contribution. For example, measurement on species specifically from ship exhausts is recommended as Nantong was located off the Yangtze River on east coast of China.

Supplementary Materials: The following are available online at http:/ /www.mdpi.com/2073-4433/9/10/373/s1, Figure S1: Chromatograph of standard sample (800 mL sample of $10 \mathrm{ppb})$, Figure S2: Chromatograph of a sample (XH site, 30 July, 14:00).

Author Contributions: Study design, J.Z. and G.S.; Data collection, J.Z., C.L., D.Z. and S.W.; Data analysis, J.Z. and Q.L.; Manuscript writing: J.Z. and Y.Z.; Project management: Q.Z.

Funding: This research was funded by the National Key Research and Development Program of China (2016YFC0201502), the Natural Science Foundation of China (21507049, 91644220 and 41575142), National Key Technology Research and Development program (2014BAC22B02), Natural Science Foundation of Jiangsu (BE2014724), and Environmental Protection Department of Jiangsu Province (2017003).

Conflicts of Interest: The authors declare no conflict of interest. 


\section{References}

1. Kim, Y.M.; Harrad, S.; Harrison, R.M. Concentrations and sources of VOCs in urban domestic and public microenvironments. Environ. Sci. Technol. 2001, 35, 997-1004. [CrossRef] [PubMed]

2. Derwent, R. Intercomparison of chemical mechanisms for air quality policy formulation and assessment under North American conditions. J. Air Waste Manag. Assoc. 2017, 67, 789-796. [CrossRef] [PubMed]

3. Malley, C.S.; Barban, C.F.; Dumitrean, P.; Cape, J.N.; Heal, M.R. The impact of speciated VOCs on regional ozone increment derived from measurements at the UK EMEP supersites between 1999 and 2012. Atmos. Chem. Phys. 2015, 15, 8361-8380. [CrossRef]

4. Mazzuca, G.M.; Ren, X.; Loughner, C.P.; Estes, M.; Crawford, J.H. Ozone production and its sensitivity to NOx and VOCs: Results from the DISCOVER-AQ field experiment, Houston 2013. Atmos. Chem. Phys. 2016, 16, 14463-14474. [CrossRef]

5. Zhang, J.; Dabek-Zlotorzynska, E.; Liggio, J.; Stroud, C.A.; Charland, J.P.; Brook, J.R. Use of the integrated organic gas and particle sampler to improve the characterization of carbonaceous aerosol in the near-road environment. Atmos. Environ. 2016, 126, 192-199. [CrossRef]

6. Robinson, A.L.; Donahue, N.M.; Shrivastava, M.K.; Weitkamp, E.A.; Sage, A.M.; Grieshop, A.P.; Lane, T.E.; Pierce, J.R.; Pandis, S.N. Rethinking organic aerosols: Semivolatile emissions and photochemical aging. Science 2007, 315, 1259-1262. [CrossRef] [PubMed]

7. Ait-Helal, W.; Borbon, A.; Sauvage, S.; de Gouw, J.A.; Colomb, A.; Gros, V.; Freutel, F.; Crippa, M.; Afif, C.; Baltensperger, U.; et al. Volatile and intermediate volatility organic compounds in suburban Paris: Variability, origin and importance for SOA formation. Atmos. Chem. Phys. 2014, 14, 10439-10464. [CrossRef]

8. Zhang, Q.J.; Beekmann, M.; Drewnick, F.; Freutel, F.; Schneider, J.; Crippa, M.; Prevot, A.S.H.; Baltensperger, U.; Poulain, L.; Wiedensohler, A.; et al. Formation of organic aerosol in the Paris region during the MEGAPOLI summer campaign: Evaluation of the volatility basis-set approach within the CHIMERE model. Atmos. Chem. Phys. 2013, 13, 5767-5790. [CrossRef]

9. Sun, J.; Wu, F.; Hu, B.; Tang, G.; Zhang, J.; Wang, Y. VOC characteristics, emissions and contributions to SOA formation during hazy episodes. Atmos. Environ. 2016, 141, 560-570. [CrossRef]

10. Wang, T.; Xue, L.; Brimblecombe, P.; Lam, Y.F.; Li, L.; Zhang, L. Ozone pollution in China: A review of concentrations, meteorological influences, chemical precursors, and effects. Sci. Total Environ. 2017, 575, 1582-1596. [CrossRef] [PubMed]

11. Li, L.; An, J.Y.; Shi, Y.Y.; Zhou, M.; Yan, R.S.; Huang, C.; Wang, H.L.; Lou, S.R.; Wang, Q.; Lu, Q.; et al. Source apportionment of surface ozone in the Yangtze River Delta, China in the summer of 2013. Atmos. Environ. 2016, 144, 194-207. [CrossRef]

12. Jin, X.; Holloway, T. Spatial and temporal variability of ozone sensitivity over China observed from the Ozone Monitoring Instrument. J. Geophys. Res. Atmos. 2015, 120, 7229-7246. [CrossRef]

13. Zhou, Y.; Zhao, Y.; Mao, P.; Zhang, Q.; Zhang, J.; Qiu, L.; Yang, Y. Development of a high-resolution emission inventory and its evaluation and application through air quality modeling for Jiangsu Province, China. Atmos. Chem. Phys. 2017, 17, 211-233. [CrossRef]

14. Zhao, Y.; Mao, P.; Zhou, Y.; Yang, Y.; Zhang, J.; Wang, S.; Dong, Y.; Xie, F.; Yu, Y.; Li, W. Improved provincial emission inventory and speciation profiles of anthropogenic non-methane volatile organic compounds: A case study for Jiangsu. China Atmos. Chem. Phys. 2017, 17, 7733-7756. [CrossRef]

15. An, J.; Zhu, B.; Wang, H.; Li, Y.; Lin, X.; Yang, H. Characteristics and source apportionment of VOCs measured in an industrial area of Nanjing, Yangtze River Delta, China. Atmos. Environ. 2014, 97, 206-214. [CrossRef]

16. Huang, C.; Chen, C.H.; Li, L.; Cheng, Z.; Wang, H.L.; Huang, H.Y.; Streets, D.G.; Wang, Y.J.; Zhang, G.F.; Chen, Y.R. Emission inventory of anthropogenic air pollutants and VOC species in the Yangtze River Delta region, China. Atmos. Chem. Phys. 2011, 11, 4105-4120. [CrossRef]

17. Zhang, Q.; Streets, D.G.; Carmichael, G.R.; He, K.B.; Huo, H.; Kannari, A.; Klimont, Z.; Park, I.S.; Reddy, S.; Fu, J.S.; et al. Asian emissions in 2006 for the NASA INTEX-B mission. Atmos. Chem. Phys. 2009, 9, 5131-5153. [CrossRef]

18. Li, J.; Xie, S.D.; Zeng, L.M.; Li, L.Y.; Li, Y.Q.; Wu, R.R. Characterization of ambient volatile organic compounds and their sources in Beijing, before, during, and after Asia-Pacific Economic Cooperation China 2014. Atmos. Chem. Phys. 2015, 15, 7945-7959. [CrossRef] 
19. Bo, Y.; Cai, H.; Xie, S.D. Spatial and temporal variation of historical anthropogenic NMVOCs emission inventories in China. Atmos. Chem. Phys. 2008, 8, 7297-7316. [CrossRef]

20. Wang, M.; Shao, M.; Chen, W.; Yuan, B.; Lu, S.; Zhang, Q.; Zeng, L.; Wang, Q. A temporally and spatially resolved validation of emission inventories by measurements of ambient volatile organic compounds in Beijing, China. Atmos. Chem. Phys. 2014, 14, 5871-5891. [CrossRef]

21. Ou, J.; Zheng, J.; Li, R.; Huang, X.; Zhong, Z.; Zhong, L.; Lin, H. Speciated OVOC and VOC emission inventories and their implications for reactivity-based ozone control strategy in the Pearl River Delta region, China. Sci. Total Environ. 2015, 530-531, 393-402. [CrossRef] [PubMed]

22. Louie, P.K.K.; Ho, J.W.K.; Tsang, R.C.W.; Blake, D.R.; Lau, A.K.H.; Yu, J.Z.; Yuan, Z.; Wang, X.; Shao, M.; Zhong, L. VOCs and OVOCs distribution and control policy implications in Pearl River Delta region, China. Atmos. Environ. 2013, 76, 125-135. [CrossRef]

23. Zheng, J.; Chang, M.; Xie, H.; Guo, P. Exploring the spatiotemporal characteristics and control strategies for volatile organic compound emissions in Jiangsu, China. J. Clean. Prod. 2016, 127, 249-261. [CrossRef]

24. Li, L.; Xie, S.; Zeng, L.; Wu, R.; Li, J. Characteristics of volatile organic compounds and their role in ground-level ozone formation in the Beijing-Tianjin-Hebei region, China. Atmos. Environ. 2015, 113, $247-254$. [CrossRef]

25. Liu, Y.; Shao, M.; Lu, S.; Chang, C.; Wang, J.; Chen, G. Volatile Organic Compound (VOC) measurements in the Pearl River Delta (PRD) region, China. Atmos. Chem. Phys. 2008, 8, 1531-1545. [CrossRef]

26. An, J.; Wang, J.; Zhang, Y.; Zhu, B. Source Apportionment of Volatile Organic Compounds in an Urban Environment at the Yangtze River Delta, China. Arch. Environ. Contam. Toxicol. 2017, 72, 335-348. [CrossRef] [PubMed]

27. Ran, L.; Zhao, C.; Geng, F.; Tie, X.; Tang, X.; Peng, L.; Zhou, G.; Yu, Q.; Xu, J.; Guenther, A. Ozone photochemical production in urban Shanghai, China: Analysis based on ground level observations. J. Geophys. Res. 2009, 114, D15301. [CrossRef]

28. United States Environmental Protection Agency (US EPA). Compendium Method TO-15 Determination of Volatile Organic Compounds (VOCs) in Air Collected in Specially-Prepared Canisters and Analyzed by GC/MS. 1999. Available online: http://www.epa.gov/ttnamtil/files/ambient/airtox/to-15r.pdf (accessed on 1 August 2018).

29. Paatero, P.; Tapper, U. Positive matrix factorization: A non negativefactor model with optimal utilization of error estimates of data values. Envirometrics 1994, 5, 111-126. [CrossRef]

30. Barletta, B.; Meinardi, S.; Rowland, F.S.; Chan, C.; Wang, X.; Zou, S.; Chan, L.Y.; Blake, D. Volatile organic compounds in 43 Chinese cities. Atmos. Environ. 2005, 39, 5979-5990. [CrossRef]

31. Xia, L.; Cai, C.; Zhu, B.; An, J.; Li, Y.; Li, Y. Source apportionment of VOCs in a suburb of Nanjing, China, in autumn and winter. J. Atmos. Chem. 2014, 71, 175-193. [CrossRef]

32. Liu, Y.; Shao, M.; Lu, S.; Chang, C.C.; Wang, J.L.; Fu, L. Source apportionment of ambient volatile organic compounds in the Pearl River Delta, China: Part II. Atmos. Environ. 2008, 42, 6261-6274. [CrossRef]

33. Cai, C.; Geng, F.; Tie, X.; Yu, Q.; An, J. Characteristics and source apportionment of VOCs measured in Shanghai, China. Atmos. Environ. 2010, 44, 5005-5014. [CrossRef]

34. Zhang, X.M.; Xue, Z.; Li, H.; Yan, L.; Yang, Y.; Wang, Y.; Duan, J.; Li, L.; Chai, F.; Cheng, M.; et al. Ambient volatile organic compounds pollution in China. J. Environ. Sci. 2017, 55, 69-75. [CrossRef] [PubMed]

35. Carter, W.P. Development of ozone reactivity scales for volatile organic compounds. J. Air Waste Manag. Assoc. 1994, 44, 881-899. [CrossRef]

36. Grosjean, D. In situ organic aerosol formation during a smog episode: Estimated production and chemical functionality. Atmos. Environ. 1992, 26, 953-963. [CrossRef]

37. Zhang, H.; Li, H.; Zhang, Q.; Zhang, Y.; Zhang, W.; Wang, X.; Bi, F.; Chai, F.; Gao, J.; Meng, L.; et al. Atmospheric volatile organic compounds in a typical urban area of Beijing: Pollution characterization, health risk assessment and source apportionment. Atmosphere 2017, 8, 61. [CrossRef]

38. Wang, H.; Qiao, Y.; Chen, C.; Lu, J.; Dai, H.; Qiao, L.; Lou, S.; Huang, C.; Li, L.; Jing, S.; et al. Source profiles and chemical reactivity of volatile organic compounds from solvent use in Shanghai, China. Aerosol Air Qual. Res. 2014, 14, 301-310. [CrossRef]

39. Brown, S.G.; Eberly, S.; Paatero, P.; Norris, G.A. Methods for estimating uncertainty in PMF solutions: Examples with ambient air and water quality data and guidance on reporting PMF results. Sci. Total Environ. 2015, 518-519, 626-635. [CrossRef] [PubMed] 
40. Heo, J.B.; Hopke, P.K.; Yi, S.M. Source apportionment of $\mathrm{PM}_{2.5}$ in Seoul, Korea. Atmos. Chem. Phys. 2009, 9 , 4957-4971. [CrossRef]

41. Song, Y.; Shao, M.; Liu, Y.; Lu, S.; Kuster, W.; Goldan, P.; Xie, S. Source apportionment of ambient volatile organic compounds in Beijing. Environ. Sci. Technol. 2007, 41, 4348-4353. [CrossRef] [PubMed]

42. McCarthy, M.C.; Aklilu, Y.A.; Brown, S.G.; Lyder, D.A. Source apportionment of volatile organic compounds measured in Edmonton, Alberta. Atmos. Environ. 2013, 81, 504-516. [CrossRef]

43. Choi, Y.J.; Ehrman, S.H. Investigation of sources of volatile organic carbon in the Baltimore area using highly time-resolved measurements. Atmos. Environ. 2004, 38, 775-791. [CrossRef]

44. Zhong, Z.; Sha, Q.; Zheng, J.; Yuan, Z.; Gao, Z.; Ou, J.; Zheng, Z.; Li, C.; Huang, Z. Sector-based VOCs emission factors and source profiles for the surface coating industry in the Pearl River Delta region of China. Sci. Total Environ. 2017, 583, 19-28. [CrossRef] [PubMed]

(C) 2018 by the authors. Licensee MDPI, Basel, Switzerland. This article is an open access article distributed under the terms and conditions of the Creative Commons Attribution (CC BY) license (http://creativecommons.org/licenses/by/4.0/). 